\title{
Effects of Small Amounts of B, Nb and Ti Additions on Nucleation and Growth Processes of Intermediate Transformation Products in Low Carbon 3\% Mn Steels
}

\author{
Yun Chul JUNG, Hiroaki UENO, Hiroyuki OHTSUBO, (1) Kiyomichi NAKAI" ${ }^{1)}$ and Yasuya OHMORI') \\ Graduate Student, Ehime University, Bunkyo-cho, Matsuyama, Ehime-ken, 790 Japan. \\ 1) Department of Materials Science and Engineering, Faculty of Engineering, Ehime University, Bunkyo-cho, Matsuyama, \\ Ehime-ken, 790 Japan.
}

(Received on March 2, 1995; accepted in final form on May 26, 1995)

\begin{abstract}
The formation mechanism of intermediate transformation products and the effects of $B$ as well as carbide forming elements such as $\mathrm{Cr}, \mathrm{Nb}$ and $\mathrm{Ti}$ on the isothermal transformation characteristics of low carbon $3 \mathrm{wt} \% \mathrm{Mn}$ steels have been investigated and the following results have been obtained.

(1) Widmanstätten ferrite and bainite exibit both the diffusional and the displacive aspects in their formation processes.

(2) The addition of the above described elements markedly retards the formation of primary ferrite, Widmanstätten ferrite and bainite in the specimens directly quenched to isothermal transformation temperatures from $1200^{\circ} \mathrm{C}$, while the precipitation of coarse carbide particles in austenite accelerates the following transformations.

(3) Ferrite nucleation on coarse carbide particles can be explained in terms of the decrease in the activation energy for nucleation by the lattice correspondence at the interface.

(4) The coarse carbide particles precipitated at austenite grain boundaries are related to the ferrite enclosing these particles with Kurdjumov-Sachs relationship.
\end{abstract}

KEY WORDS: carbide forming elements; isothermal transformation; intermediate transformation products; grain boundary carbide; orientation relationship.

\section{Introduction}

The isothermal decomposition behaviours of intermediate transformation products such as Widmanstätten ferrite and bainite in medium and high carbon steels have been considerably well understood. ${ }^{1-4)}$ However the microstructures of the low carbon low alloy high strength steels produced by thermomechanical control process (TMCP) are quite fine and complex, the structures being difficult to classify. ${ }^{5,6)}$ In addition to it, these steels often contain small amounts of $\mathrm{B}, \mathrm{Nb}$ and $\mathrm{Ti}$ to get high strength. ${ }^{7,8)}$ It has been well established that boron atoms segregating at austenite grain boundaries retard the primary ferrite nucleation and enhance hardenability. ${ }^{9-12)} \mathrm{Nb}$ and $\mathrm{Ti}$ on the other hand, are strong carbide forming elements and the dispersion of these fine carbide particles induces large precipitation hardening. The effect of these atoms on hardenability, however, is not well understood and is also of interest to examine.

The aims of the present study are, therefore, to examine the effects of various elements such as $\mathrm{B}, \mathrm{Nb}, \mathrm{Ti}$ and $\mathrm{Cr}$ and of preexisting coarse carbide particles on the phase transformation behaviour and to discuss the austenite decomposition mechanisms by the microstructural observations in low carbon $3 \mathrm{wt} \%$ Mn steels.

\section{Experimental Procedures}

The chemical compositions of the steels used in the present investigation are given in Table 1. These steels were received as hot-rolled $15 \mathrm{~mm}$ thick, $100 \mathrm{~mm}$ wide plates prepared by the Bainite Committee of The Iron and Steel Institute of Japan. All of the steels contain $0.04 \mathrm{wt} \% \mathrm{C}$ and $3 \mathrm{wt} \% \mathrm{Mn}$, the differences being in the additions of $\mathrm{B}$ and carbide forming elements such as $\mathrm{Cr}$, $\mathrm{Nb}$ and Ti. Extremely small amounts of $\mathrm{B}$ below $3 \mathrm{ppm}$ in MS 2, MS 3 and MS 7 were unintentional residuals, and their effects were ignored in the present study. Specimens of $3 \mathrm{~mm}$ thick, $5 \mathrm{~mm}$ wide and $15 \mathrm{~mm}$ long

Table 1. Chemical compositions of the steels used. (wt \%)

\begin{tabular}{lccccccccc}
\hline Mark & $\mathrm{C}$ & $\mathrm{Si}$ & $\mathrm{Mn}$ & $\mathrm{Cr}$ & $\mathrm{Nb}$ & $\mathrm{Ti}$ & $\mathrm{B}$ & $\mathrm{Al}$ & $\mathrm{N}$ \\
\hline MS 2 & 0.040 & 0.20 & 2.95 & - & - & 0.002 & 0.0003 & 0.017 & 0.0019 \\
MS 3 & 0.040 & 0.20 & 2.94 & - & 0.028 & 0.023 & 0.0002 & 0.017 & 0.0018 \\
MS 7 & 0.039 & 0.20 & 2.99 & 1.00 & 0.030 & 0.020 & 0.0002 & 0.018 & 0.0008 \\
MS10 & 0.040 & 0.20 & 3.00 & 1.00 & 0.030 & 0.0210 & 0.0013 & 0.019 & 0.0009
\end{tabular}




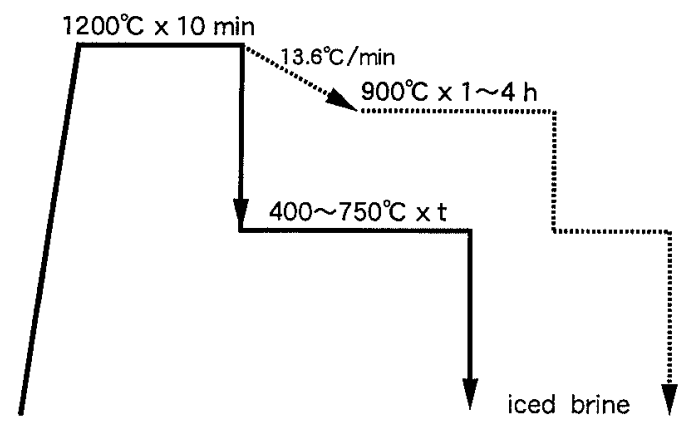

Fig. 1. Heat treatment patterns.

Solid line: Direct transformation after $1200^{\circ} \mathrm{C}$ austenitization. Broken line: Transformation of the specimens isothermally held at $900^{\circ} \mathrm{C}$ after $1200^{\circ} \mathrm{C}$ austenitization. The preheat-treatment was carried out to examine the effect of coarse carbide particles on isothermal decomposition processes.

were machined from them and heat treated as follows. The specimens were austenitized at $1200^{\circ} \mathrm{C}$ for $10 \mathrm{~min}$ in a dynamic nitrogen atmosphere and were quenched into either a lead or an alloy bath kept isothermally at various temperatures between 400 and $750^{\circ} \mathrm{C}$. After holding for various periods, the specimens were finally quenched into iced brine to freeze the untransformed austenite as martensite (solid line in Fig. 1).

In order to examine the effects of preexisting coarse carbide particles on austenite decomposition processes, the specimens solution treated at $1200^{\circ} \mathrm{C}$ were cooled to $900^{\circ} \mathrm{C}$ at the cooling rate of $13.6^{\circ} \mathrm{C} / \mathrm{min}$ in a furnace and were then held at $900^{\circ} \mathrm{C}$ for $4 \mathrm{~h}$ (preheat-treatment) in order to precipitate the carbide particles in austenite. After holding, the specimens were isothermally transformed at temperatures where intermediate transformation products form and were finally quenched into iced brine (broken line in Fig. 1).

The cross sections of the heat treated specimens were polished, etched in 3\% nital for the microstructural observations by optical microscopy. In order to construct T.T.T. diagrams, the amounts of transformation products were measured by an image analyzer (linear analysis method) using 4 micrographs with magnification 400 times taken from the central regions of the etched specimens. The thin foils for transmission electron microscopy were prepared from these specimens by means of twin-jet technique in the electrolyte consisting of $5 \%$ perchloric acid $-95 \%$ acetic acid at $13^{\circ} \mathrm{C}$. The observations were carried out by a JEM 2000 EX electron microscope operated at $200 \mathrm{kV}$.

\section{Experimental Results}

\subsection{T.T.T. Diagrams}

Figure 2 shows the effects of alloying elements and the preheat-treatment on the T.T.T. diagrams for these steels. The C-curves for the isothermal transformations directly after the austenitization at $1200^{\circ} \mathrm{C}$ are shown as solid lines. MS 2 which does not contain $\mathrm{Cr}, \mathrm{Nb}, \mathrm{Ti}$ and $\mathrm{B}$ exhibits two clearly separate C-curves for both primary ferrite above $600^{\circ} \mathrm{C}$ and bainite at temperatures between $600^{\circ} \mathrm{C}$ and Ms point (Fig. 2(a)). In the case of MS 3 which contains small amounts of both $\mathrm{Nb}$ and $\mathrm{Ti}$, similar

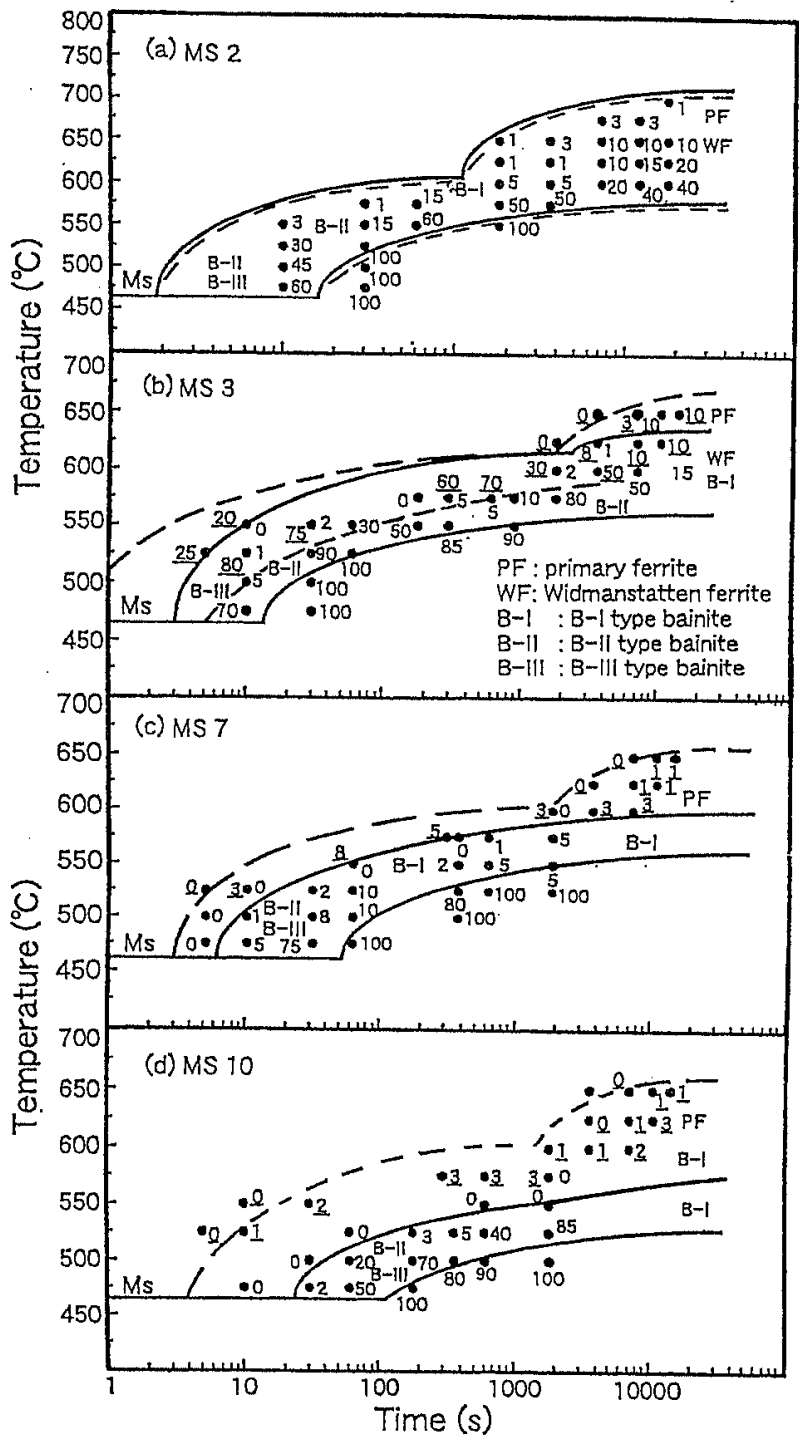

Fig. 2. Time-Temperature-Transformation diagrams. Solid lines indicate the direct transformations from $1200^{\circ} \mathrm{C}$, and broken lines show the transformations after the isothermal holding at $900^{\circ} \mathrm{C}$ for $4 \mathrm{~h}$. The numbers within the diagrams indicate the amounts of transformation in percentage.

reactions can be recognized with a significant retardation of primary ferrite formation as in Fig. 2(b). As can be seen in Fig. 2(c), by adding $1 \mathrm{wt} \% \mathrm{Cr}$ to MS 3 (MS 7), the primary ferrite formation could not be detected within the time period examined. The addition of $13 \mathrm{ppm} \mathrm{B}$ to MS 7 (MS 10) also retards bainitic reaction significantly as in Fig. 2(d).

The broken lines in Fig. 2 show the C-curves for the materials which were held at $900^{\circ} \mathrm{C}$ for $4 \mathrm{~h}$ to form coarse carbide particles after the austenitization at $1200^{\circ} \mathrm{C}$ and isothermally transformed at temperatures between 400 and $750^{\circ} \mathrm{C}$. Although preheat-treatment dose not affect the transformation characteristics of MS 2 which does not contain any strong carbide forming element, drastic effect can be recognized in the other steels. Except in the case of MS 2, the formation of primary ferrite is much accelerated by the preheattreatment even in MS which contain both B and all the carbide forming elements. Both Bs and Ms points, 

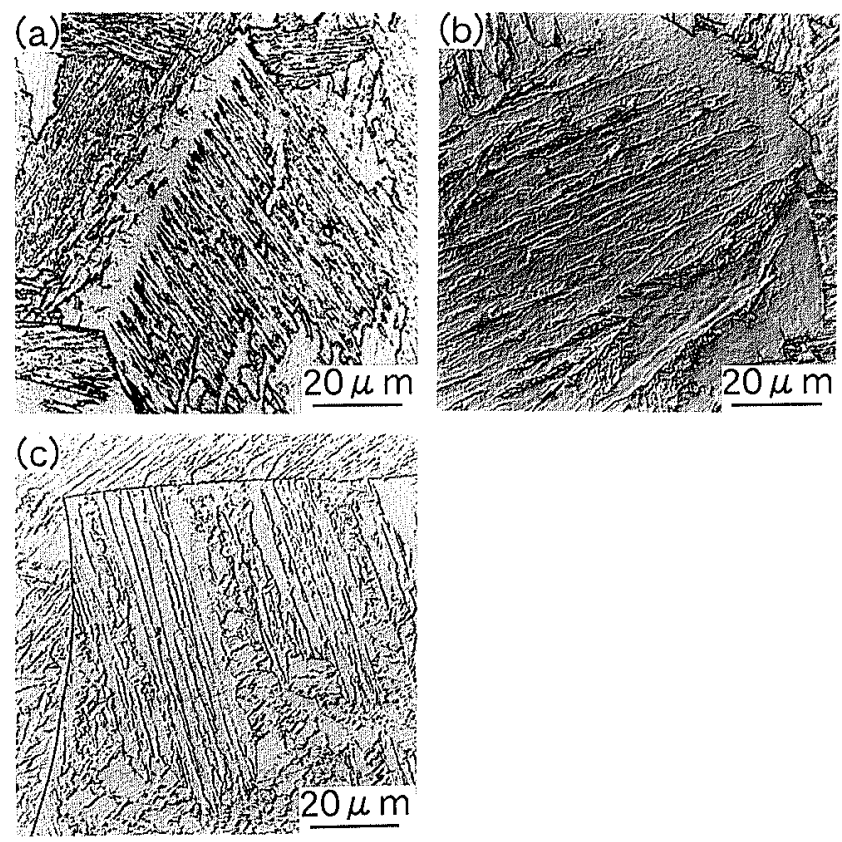

Fig. 3. Optical micrographs of the specimens directly transformed from $1200^{\circ} \mathrm{C}$. (a) MS 2 transformed at $600^{\circ} \mathrm{C}$ for $300 \mathrm{~s}$, (b) MS 2 transformed at $600^{\circ} \mathrm{C}$ for $1800 \mathrm{~s}$ and (c) MS 10 transformed at $475^{\circ} \mathrm{C}$ for $180 \mathrm{~s}$.

however, are not affected significantly by this treatment, the Bs points being almost constant at approximately $600^{\circ} \mathrm{C}$

\subsection{Microstructures}

Figure 3 shows the microstructures of the specimens isothermally transformed at temperatures between 600 and $475^{\circ} \mathrm{C}$ after the austenitization at $1200^{\circ} \mathrm{C}$ in MS 2 and MS 3, respectively. As can be seen in Fig. 3(a), primary ferrite forms along the prior austenite grain boundary at the beginning stage of the transformation and Widmanstätten ferrite laths of a specific orientation grow subsequently from them into a austenite grain. The laths are rather thin and very straight. Figure 3(b) shows the later stage of transformation at this temperature. Widmanstätten ferrite laths grow in size and become thick in comparison with those in Fig. 3(a), the subgrain boundaries being often observed within them. This implies that the thicker laths were formed by the coalescence of thin laths via short range diffusion.

Bainite, however, nucleates directly at the austenite grain boundaries at temperatures between $600^{\circ} \mathrm{C}$ and $\mathrm{Ms}$ point, and the types of its morphology were B-I, B-II and B-III as classified by Ohmori et al. ${ }^{13)}$ In the previous paper, ${ }^{14)}$ it has been shown that both Widmanstätten ferrite and bainite accompanied very sharp and straight surface reliefs of the invariant plane strain type as that of martensite. This result indicates that the growth processes in these transformation products may be partially related to some shear modes ${ }^{15,16)}$ as well as the diffusional mode such as the C-curves shown in Fig. 2.

Figure 4 shows the optical micrographs of the specimens isothermally transformed at $610^{\circ} \mathrm{C}$ for $3 \mathrm{~h}$ after the preheat-treatment. By this treatment, primary ferrite forms along the prior austenite grain boundaries (Fig. 4(a)). Carbide like coarse precipitates can often be
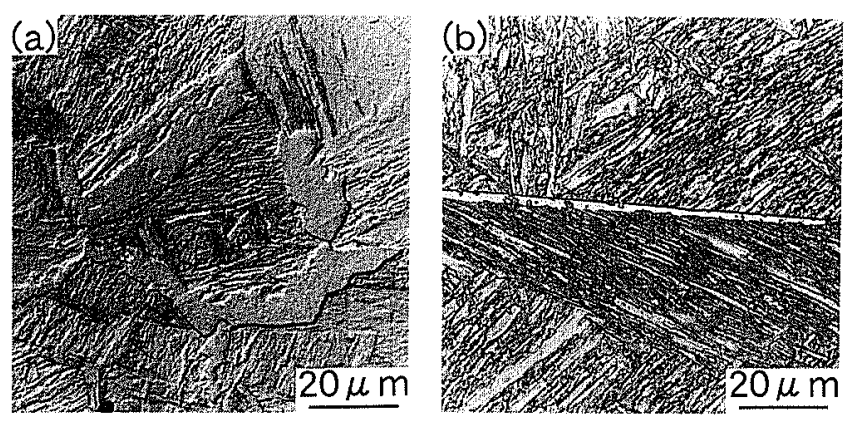

Fig. 4. Optical micrographs of the specimens isothermally transformed at $610^{\circ} \mathrm{C}$ for $3 \mathrm{~h}$ after the preheattreatment. (a) Primary ferrite formed along the prior austenite grain boundary in MS 3. (b) Coarse particles were observed within a grain boundary ferrite allotriomorph in MS 7.
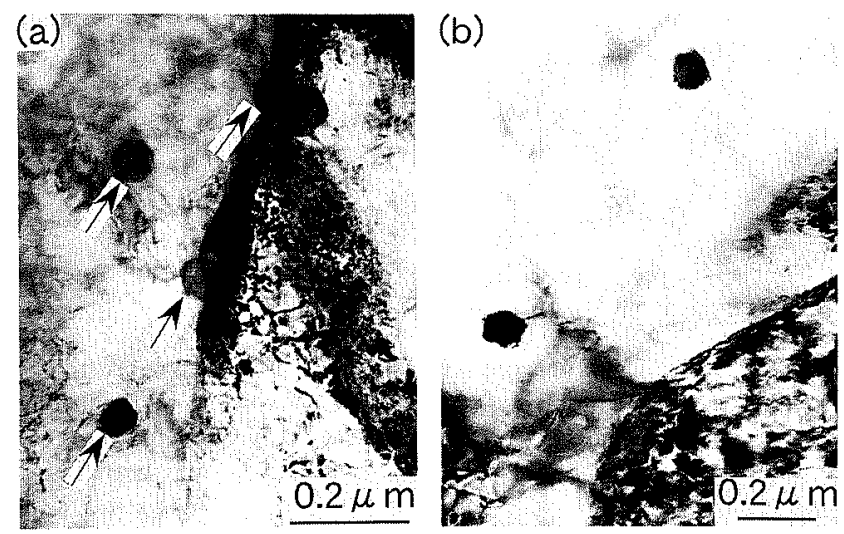

Fig. 5. Transmission electron micrographs of MS 3. (a) Directly quenched into iced brine, and (b) transformed isothermally at $610^{\circ} \mathrm{C}$ for $3 \mathrm{~h}$ after the preheattreatment.

observed in the vicinity of the austenite grain boundaries or within the primary ferrite grains as in Fig. 4(b). Figure 5 shows the transmission electron micrographs of MS 3 preheat-treated at $900^{\circ} \mathrm{C}$. In the specimen directly quenched into iced brine after the preheat-treatment, coarse carbide particles can be seen on or around a prior austenite grain boundary indicated as arrows in Fig. 5(a). These carbide particles, however, could never be observed in the specimens directly quenched into iced brine or transformed at $600^{\circ} \mathrm{C}$ for up to $3 \mathrm{~h}$ after the austenitization at $1200^{\circ} \mathrm{C}$. In the specimen isothermally transformed at $610^{\circ} \mathrm{C}$ for $3 \mathrm{~h}$ after the pre-treatment, these coarse carbide particles distributed on a prior austenite grain boundary plane were enclosed by ferrite as shown in Fig. 5(b).

It should also be noted that the incubation time to start bainite reaction is reduced by this preheattreatment. From these results, it is likely that the precipitation of coarse carbide particles around austenite grain boundary prior to transformation accelerates both primary ferrite and bainitic ferrite formation, suggesting that these coarse carbide particles precipitated at austenite grain boundaries can be potential nucleation sites for ferrite. Figures 6(a) through 6(d) are the bright field image, the selected area diffraction pattern, the schematic illustration and its stereographic analysis, 


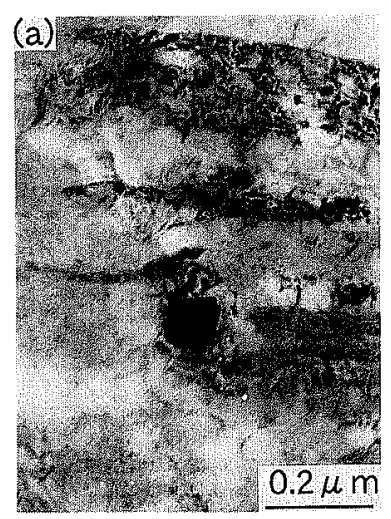

(c)

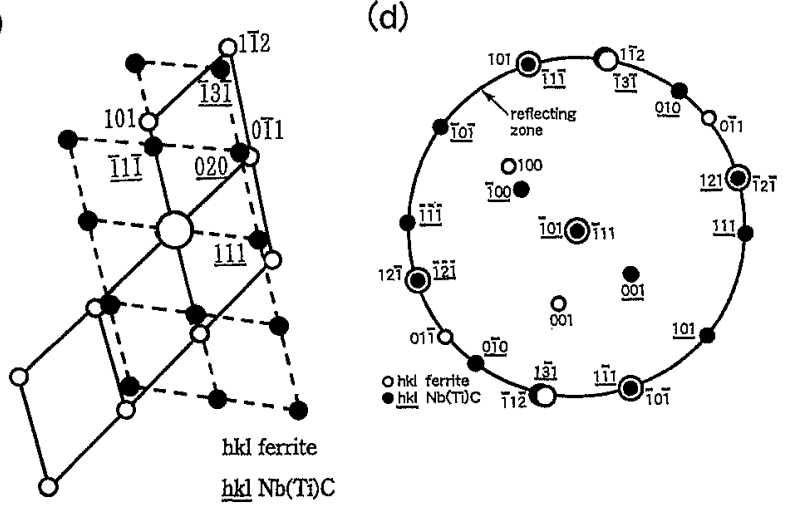

Fig. 6. TEM micrographs of MS 3 isothermally transformed at $610^{\circ} \mathrm{C}$ for $3 \mathrm{~h}$ after the preheat-treatment. (a) Bright field image, (b) selected area diffraction pattern, (c) schematic illustration and (d) its stereographic analysis.

respectively. The carbide particle enclosed by primary ferrite was identified as $\mathrm{Nb}$ and/or Ti carbide by the selected area diffraction pattern shown in Fig. 6(b). Since $\mathrm{NbC}$ and $\mathrm{TiC}$ have the same $\mathrm{NaCl}$ type lattice with the lattice constants of 4.47 and $4.32 \AA$, respectively, it is difficult to separate them by these diffraction patterns. However, (111), (121) and (13ī) planes of $\mathrm{NbC}$ or TiC

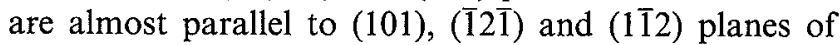
the ferrite, respectively, as can be seen in Fig. 6(c). This result leads to the Kurdjumov-Sachs ${ }^{17)}$ relationship between carbide and ferrite as in Fig. 6(d).

\section{Discussion}

\subsection{Retardation of Ferrite Formation}

The additions of $\mathrm{B}$ and carbide forming elements such as $\mathrm{Cr}, \mathrm{Nb}$ and $\mathrm{Ti}$ suppressed the primary ferrite formation, and shifted the C-curves for bainite to longer holding time as shown in Fig. 2. However, it is quite difficult to examine the effects of each elements in details in the case of the system containing many components. It has been well established that B atoms segregate to an austenite grain boundary and suppress the primary ferrite nucleation by reducing the interface energy. ${ }^{9-12)}$ In fact, the retardation of bainitic reaction can be seen clearly by comparing the solid C-curves in Figs. 2(c) and 2(d). Since the amounts of $B$ atoms segregating to the grain boundary at temperatures as high as $1200^{\circ} \mathrm{C}$ are though to be insufficient to suppress the ferrite formation, it is likely that additional segregation occurs during cooling to transformation temperatures. ${ }^{18)}$

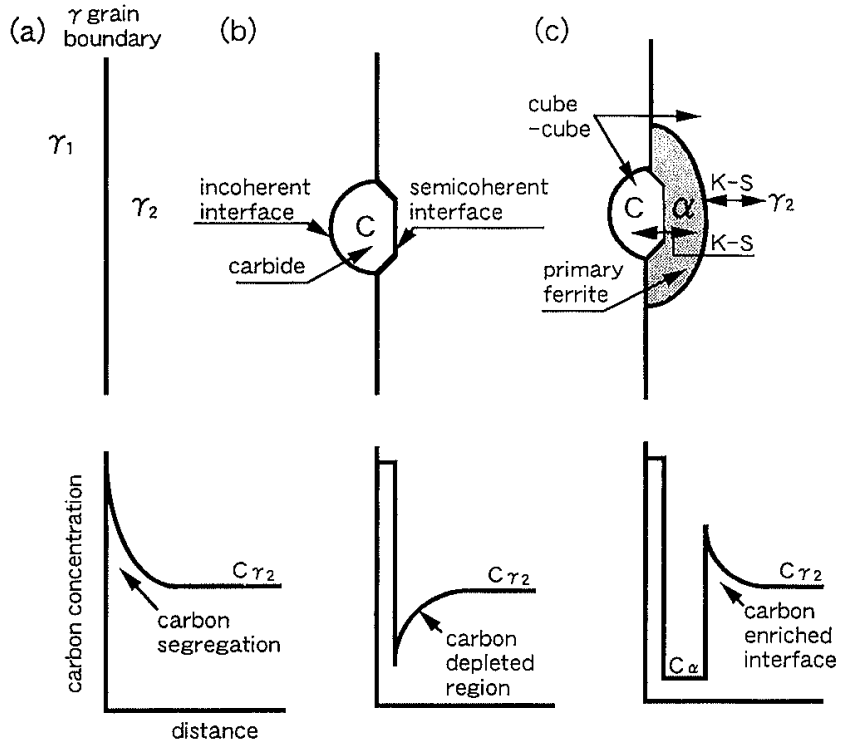

Fig. 7. Schematic illustration of the decomposition processes at an austenite grain boundary and carbon concentration profiles. (a) Austenite grain boundary, (b) carbide precipitation at the boundary, and (c) ferrite nucleation at a semicoherent austenite/carbide interface.

Similar effects of small amounts of $\mathrm{Nb}$ and/or Ti can be recognized by comparing MS 2 and MS 3 as indicated by solid lines in Figs. 2(a) and 2(b). In this case, however, since the diffusion constants of both $\mathrm{Nb}$ and $\mathrm{Ti}$ are much smaller than that of interstitial $\mathrm{B}$ atoms, the grain boundary segregation of these elements at $1200^{\circ} \mathrm{C}$ will dominate the transformation characteristics. On the mechanism to suppress the ferrite nucleation, there may be two possibilities. The one is the grain boundary segregation of $\mathrm{Nb}$ and $\mathrm{Ti}$, and the other is the precipitation of fine $\mathrm{Nb}$ and/or Ti carbo-nitride particles at the austenite grain bundaries and also at the austenite/ferrite interface boundary. ${ }^{19)}$ Since the solubility products of $\mathrm{NbC}$ and $\mathrm{TiC}$ in austenite are rather small, the precipitation of these carbide particles will occur easily at the austenite grain boundaries, the occurrence of the latter being more likely. That is, extremely fine carbide particles precipitating almost continuously at austenite grain boundaries with a specific orientation relationship may prevent the nucleation of primary ferrite formation as has been postulated by Sharma et al. ${ }^{20)}$ the incoherent austenite grain boundaries being covered by the coherent carbide/austenite interfaces.

\subsection{Acceleration Mechanism of Ferrite Formation by Coarse Carbides}

The precipitation of coarse $\mathrm{NbC}$ and/or TiC particles by the preheat-treatment on austenite grain boundaries accelerated both primary ferrite and bainitic ferrite formations as indicated by broken lines in Figs. 2(b) through 2(d). The progress of the transformation in the vicinity of an austenite grain boundary can be depicted as in Fig. 7. The lower part in Fig. 7 shows the variation of carbon concentrations. While the specimen is cooled from 1200 to $900^{\circ} \mathrm{C}$, interstitial atoms such as carbon segregate to the austenite grain boundaries where the lattice is distorted. If the specimen contains strong carbide forming elements such as $\mathrm{Nb}$ and $\mathrm{Ti}$ which are 
also segregated to the boundaries, carbide particles will precipitate there. By holding at $900^{\circ} \mathrm{C}$ for long time, these precipitates grow in size as shown in Fig. 7(b). The carbon concentration profile around the carbide particle will change, the carbon depleted region being formed in austenite at the carbide interface. The NaCl-type coarse carbide particles which form at an austenite grain boundary are related to either of the grains separated by the boundary with cube-cube orientation relationship. ${ }^{21)}$ It is interesting to note that the inferfacial energy for incoherent carbide/austenite interface is higher than that for coherent or semicoherent one. This implies that the driving force for the transformation from austenite to ferrite is significantly large in the case of the incoherent interface.

The orientation relationship between the coarse $\mathrm{Nb}$ and/or Ti carbide particle and the ferrite enclosing it was of Kurdjumov-Sachs type. ${ }^{17)}$ Assuming that the ferrite was related to the austenite with $\mathrm{K}-\mathrm{S}$ relationship, these carbide should be related to the austenite by the cubecube relationship. This indicates that the ferrite nucleated at the semicoherent carbide/austenite interface which provided rather small driving force. Tanino et al. ${ }^{22,23)}$ pointed out that the atomic configuration on a $\{100\}$ plane of the NaCl-type carbide is almost similar to that on a $\{100\}$ ferrite plane. Therefore, the activation energy to nucleate a ferrite on such a semicoherent carbide/ austenite inferface will be much reduced in comparison with that for the nucleation on an incoherent interface. Thus the activation energy rather than the driving force for nucleation is thought to control the ferrite nucleation at the present transformation temperatures.

\section{Conclusions}

The effects of B and carbide forming elements such as $\mathrm{Cr}, \mathrm{Nb}$ and $\mathrm{Ti}$ and also the coarse grain boundary carbide particles on the isothermal transformation characteristics in low carbon $3 \mathrm{wt} \% \mathrm{Mn}$ steels have been investigated and the following results were obtained.

(1) The small additions of $\mathrm{Nb}$ and/or Ti suppress the primary ferrite formation but do not affect significantly bainitic transformation. The addition of $1 \mathrm{wt} \% \mathrm{Cr}$, on the other hand, retards both primary ferrite and bainitic ferrite nucleations.

(2) The grain boundary segregation of B atoms also retards bainitic ferrite formation probably by reducing the grain boundary energy in austenite.

(3) Coarse NbC and/or TiC particles formed at a prior austenite grain boundary accelerate ferrite nucleation on their interfaces.

(4) The coarse carbide particles, i.e., $\mathrm{NbC}$ and/or $\mathrm{TiC}$, are related to the ferrite enclosing them with Kurdjumov-Sachs relationship, suggesting that the ferrite nucleates at a semicoherent carbibe/austenite interface. Such a situation may arise from the fact that the activation energy for ferrite nucleation is reduced by the coherency among ferrite, carbide and austenite.

\section{Acknowledgements}

This research has been carried out as an activity of Basic Research Committee of The Iron and Steel Institute of Japan. The materials were those for the round robin test in Bainite Research Committee of The Iron and Steel Institute of Japan and were supplied by Kobe Steel, Ltd. The authors would like to express their sincere thanks to The Iron and Steel Institute of Japan for the financial support and to Kobe Steel, Ltd. for supplying the materials. Thanks are also due to the members of the Advanced Instrumentation Center, Ehime University, for utilization of providing a JEM 2000EX electron microscope.

\section{REFERENCES}

1) H. K. D. H. Bhadeshia and D. V. Edmonds: Acta Metall., 28 (1980), 1265.

2) Y. Ohmori: Mater. Trans. JIM, 30 (1989), 487.

3) G. Spanos, H. S. Fang and H. I. Aaronson: Metall. Trans., 21A (1990), 1381.

4) Y. Ohmori and T. Maki: Mater. Trans. JIM, 32 (1991), 631.

5) T. Araki, K. Shibata and M. Enomoto: Proc. ICOMAT-89 Sydney, Mat. Sci. Forum, 56 (1991), 1284.

6) T. Araki and M. Enomoto: Proc. Mat. Tech- 90 Symp., Helsinki, 2 (1991), 1284.

7) W. E. Duckworth, R. Phillips and J. A. Chapman: J. Iron Steel Inst., 203 (1965), 1108.

8) K. J. Irvine, F. B. Pickering and T. Gladman: J. Iron Steel Inst., 205 (1967), 161.

9) R. A. Grange and A. R. T. M. Garvey: Trans. Am. Soc. Met., 37 (1946), 136.

10) C. R. Simcoe, A. R. Elsea and G. K. Manning: Trans. Metall. Soc. AIME, 203 (1955), 193.

11) J. W. Spretnak and R. Speiser: Trans. Am. Soc. Met., 46 (1954), 1089.

12) F. G. Melloy, P. R. Slimmon and P. P. Podgursky: Metall. Trans., 4 (1973), 2279.

13) Y. Ohmori, H. Ohtani and T. Kunitake: Trans. Iron Steel Inst. Jpn., 11 (1971), 250.

14) Y. C. Jung, K. Nakai, H. Ohtsubo and Y. Ohmori: Trans. Iron Steel Inst. Jpn., 34 (1994), 43.

15) Y. Ohmori, K. Nakai, H. Ohtsubo and M. Tsunofuri: Mater. Trans. JIM, 35 (1994), 238.

16) Y. Ohmori, K. Nakai and H. Ohtsubo: Proc. of an Int. Symp. on Solid-Solid Phase Transformations '94, ed. by W. C. Thonson, J. M. Howe, D. E. Laughlin and W. A. Sofa, The Minerals, Metals \& Materials Society, (1994), 905.

17) G. Kurdjumov and G. Sachs: Z. Phys., 64 (1930), 325.14.

18) D. McLean: Grain Boundary in Metals, Clarendon Press, Oxford (1957), 116

19) L. Erasmus: J. Iron Steel Inst., 202 (1964), 32.

20) R. C. Sharma and G. R. Purdy: Metall. Trans., 4A (1973), 2303.

21) D. M. Maddrill, R. N. Younger and R. G. Baker: Acta Metall., $9(1961), 982$.

22) M. Tanino, H. G. Suzuki and K. Aoki: Trans. JIM, 9 (1968), Supplement, 393.

23) T. Nshida and M. Tanino: J. Jpn. Inst. Met., 29 (1965), 728. 